University of Nebraska - Lincoln

DigitalCommons@University of Nebraska - Lincoln

Faculty Publications from the Department of Electrical \& Computer Engineering, Department Electrical and Computer Engineering

11-1-1995

\title{
Spectroscopic ellipsometric monitoring of electron cyclotron resonance plasma etching of GaAs and AlGaAs
}

\author{
Paul G. Snyder \\ University of Nebraska-Lincoln, psnyder1@unl.edu \\ Natale J. Ianno \\ University of Nebraska-Lincoln, nianno1@unl.edu \\ B. Wigert \\ University of Nebraska-Lincoln \\ S. Pittal \\ J. A. Woollam Co., Lincoln, Nebraska \\ B. Johs \\ J. A. Woollam Co., Lincoln, Nebraska \\ See next page for additional authors
}

Follow this and additional works at: https://digitalcommons.unl.edu/electricalengineeringfacpub

Part of the Electrical and Computer Engineering Commons

Snyder, Paul G.; Ianno, Natale J.; Wigert, B.; Pittal, S.; Johs, B.; and Woollam, John A., "Spectroscopic ellipsometric monitoring of electron cyclotron resonance plasma etching of GaAs and AIGaAs" (1995). Faculty Publications from the Department of Electrical and Computer Engineering. 73.

https://digitalcommons.unl.edu/electricalengineeringfacpub/73

This Article is brought to you for free and open access by the Electrical \& Computer Engineering, Department of at DigitalCommons@University of Nebraska - Lincoln. It has been accepted for inclusion in Faculty Publications from the Department of Electrical and Computer Engineering by an authorized administrator of DigitalCommons@University of Nebraska - Lincoln. 


\section{Authors}

Paul G. Snyder, Natale J. Ianno, B. Wigert, S. Pittal, B. Johs, and John A. Woollam 


\title{
Spectroscopic ellipsometric monitoring of electron cyclotron resonance plasma etching of GaAs and AIGaAs
}

\author{
P. G. Snyder, N. J. Ianno, and B. Wigert \\ Center for Microelectronic and Optical Materials Research and Department of Electrical Engineering, \\ University of Nebraska-Lincoln, Lincoln, Nebraska 68588-0511
}

S. Pittal, B. Johs, and J. A. Woollam

J. A. Woollam Co., Lincoln, Nebraska 68508

(Received 17 May 1995; accepted 18 September 1995)

\begin{abstract}
In situ real time spectroscopic ellipsometry measurements were made during electron cyclotron resonance plasma etching of radio frequency biased GaAs and AlGaAs samples. Gas mixtures used were $\mathrm{CH}_{4} / \mathrm{H}_{2} / \mathrm{Ar}$, pure $\mathrm{H}_{2}$, and pure Ar. Ellipsometry provided information about damage to the surface region and AlGaAs epilayer thickness. For the methane mixture GaAs etch, damage appeared in the form of redshifted and broadened $E_{1}$ and $E_{1}+\Delta_{1}$ critical point features in a surface layer several tens of nm thick. The damage layer began forming within a few seconds after the start of etching, and stabilized within 1 min. Hydrogen etching caused a thicker damage layer with greater redshifting and broadening, while argon caused relatively little damage. Possible mechanisms for the redshifting are discussed. During etching of an $\mathrm{AlGaAs} / \mathrm{GaAs}$ heterostructure with the methane mixture, the same redshifting and broadening effects were seen in the AlGaAs critical point structure. The AlGaAs thickness was determined from the real time data, from which an etch rate of about $20 \mathrm{~nm} / \mathrm{min}$ was derived. (C) 1995 American Vacuum Society.
\end{abstract}

\section{INTRODUCTION}

The electron cyclotron resonance (ECR) based etching of GaAs and its compounds via $\mathrm{CH}_{4} / \mathrm{H}_{2} / \mathrm{Ar}$ gas mixtures is well known. ${ }^{1}$ This gas mixture yields reasonable etch rates, is insensitive to crystal orientation, and is capable of etching a wide range of compounds. However, damage to the surface resulting from the etch process occurs. ${ }^{1}$ In order to quantify this damage we have performed a series of experiments using real time in situ spectroscopic ellipsometry (SE) to monitor ECR etching of GaAs and AlGaAs by $\mathrm{CH}_{4} / \mathrm{H}_{2} / \mathrm{Ar}$ plasmas, together with ex situ SE characterization. The effect of etching on the optical properties of the top 10-30 nm of the material was to redshift and broaden the critical point structure. The implications for the nature of the etch damage are discussed. Real time in situ SE was also used to determine the AlGaAs layer thickness, from which the etch rate was determined.

\section{EXPERIMENT}

The etching system was turbopumped by a Leybold 600 $\ell /$ s pump. The ECR system was a Microscience 900, which is a magnetic mirror type employing electromagnets and a $1000 \mathrm{~W}, 2.45 \mathrm{GHz}$ power source. Gas flow into the chamber was controlled by an MKS flow control system. The substrate was water cooled, and could be biased by a $13.56 \mathrm{MHz}$ source. The radio frequency (rf) induced direct current (dc) bias on the substrate with respect to ground was measured and maintained at a constant level throughout each etch run, and could be varied from run to run.

The in situ ellipsometer (model M-44 from J. A. Woollam Co.) was mounted on optical ports such that the light was incident on the sample at a nominal angle of $75^{\circ}$ with respect to the surface normal (the actual incidence angle was determined as described below). Detection was by 44 independent channels covering the spectral range $416-755 \mathrm{~nm}$. A scanning wavelength instrument, also from J. A. Woollam Co., was used for ex situ measurements. The supplied software incorporated the modeling and fitting features described below.

The substrates were polished (100) GaAs, either semiinsulating or doped at $2.6 \times 10^{18} \mathrm{~cm}^{-3} n$ type. The heterostructure was metalorganic chemical vapor deposition (MOCVD) grown $\mathrm{Al}_{x} \mathrm{Ga}_{1-x}$ As on GaAs, with $x$ nominally 0.35 .

Ellipsometry: Ellipsometry measures the change in polarization state of a light beam reflected at non-normal incidence from the sample surface. ${ }^{2}$ The change in polarization is given as a complex number $\rho$ related to the sample reflection properties by $\rho=R_{p} / R_{s}$, where $R_{p}\left(R_{s}\right)$ is the complex reflection coefficient for light with electric field polarized parallel (perpendicular) to the plane of incidence. Spectroscopic ellipsometry is the measure of $\rho$ as a function of photon energy $h \nu$ at one or more angles of incidence $\phi$. The $\rho$ data are sometimes converted to the pseudodielectric function for convenience:

$$
\langle\epsilon\rangle=\left\langle\epsilon_{1}\right\rangle+i\left\langle\epsilon_{2}\right\rangle=\sin ^{2} \phi\left[1+\tan ^{2} \phi\left(\frac{1-\rho}{1+\rho}\right)^{2}\right] .
$$

This is what the substrate dielectric function would be if the sample is assumed to be a simple substrate with isotropic uniform optical constants and no overlayers.

To obtain information about individual layer thicknesses and optical constants, a multilayer model is used to calculate $R_{p}$ and $R_{s}$ for comparison with the measured $\rho$ data. Selected model parameters are then varied (using the LevenburgMarquardt algorithm) to minimize an error function. ${ }^{3}$ Model parameters include layer thicknesses and dielectric functions. 


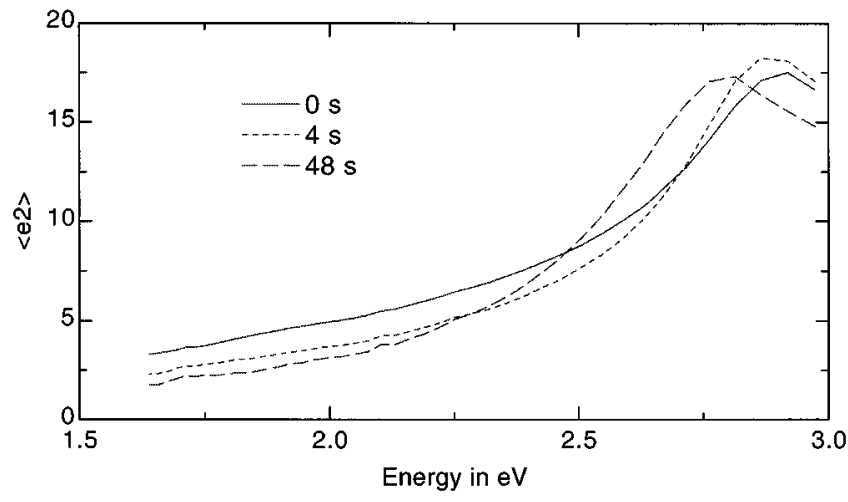

FIG. 1. In situ pseudodielectric function (imaginary part) measured during GaAs etching with the methane mixture.

The latter may themselves be modeled in various ways or tabulated by photon energy. Dielectric function models include the Bruggeman effective medium approximation (EMA) for composite or porous materials, ${ }^{4}$ a simple harmonic oscillator approximation that uses a set of Lorentz oscillator functions to approximate critical point structure, ${ }^{5}$ and an AlGaAs alloy model that allows $x$ to be varied continuously. ${ }^{6}$ The general procedure is to develop the simplest model that gives a good fit to the data, is physically reasonable, and is consistent with whatever is independently known about the sample.

\section{GaAs ETCHING}

Bulk GaAs wafers were etched as received, with no precleaning. Figure 1 shows in situ spectra measured during etching by a $\mathrm{CH}_{4} / \mathrm{H}_{2} / \mathrm{Ar}$ mixture with flow rate ratios of $5 / 15 / 7$, total pressure of $1 \mathrm{mTorr}$, microwave power of 300 $\mathrm{W}$, and $\mathrm{rf}$ induced dc bias of $-150 \mathrm{~V}$. ${ }^{1}$ The spectral range includes the $E_{1}$ critical point $(2.9 \mathrm{eV})$. The initial spectrum $(0 \mathrm{~s})$ can be modeled as normal GaAs, ${ }^{7}$ with $6 \mathrm{~nm}$ of a low index overlayer. In this initial fit, the angle of incidence (nominally $75^{\circ}$ ) was also a fitting variable. It was then fixed to the best fit value for all subsequent modeling. As etching begins, the overlayer thickness is quickly reduced $(4 \mathrm{~s})$. This is evidenced in the $\left\langle\epsilon_{2}\right\rangle$ spectrum as an amplitude increase at energies near $E_{1}$ and an amplitude decrease at lower energies. Also at $4 \mathrm{~s}$, a slight redshift and broadening of the $E_{1}$ peak are observable. The redshifting and broadening continue until both have nearly stabilized at $48 \mathrm{~s}$.

Figure 2 shows the second derivative with respect to photon energy of $\left\langle\epsilon_{2}\right\rangle$ from ex situ measurements after etching with the methane mixture. A distinct redshift (about $50 \mathrm{meV}$ ) and broadening of the $E_{1}, E_{1}+\Delta_{1}$ structure are evident. The redshift is not an artifact due to a difference in overlayer thickness. Changing the overlayer thickness moves $\left\langle\epsilon_{2}\right\rangle$ up or down but does not significantly shift the peak energies. Also shown are data from a sample etched in pure hydrogen at a pressure of $0.5 \mathrm{mTorr}, 300 \mathrm{~W}$ microwave power, and -100 $\mathrm{V}$ dc bias, and a sample etched in pure argon at a pressure of 1 mTorr, $200 \mathrm{~W}$ microwave power, and $-100 \mathrm{~V}$ dc bias. Hydrogen etching causes more pronounced redshifting and

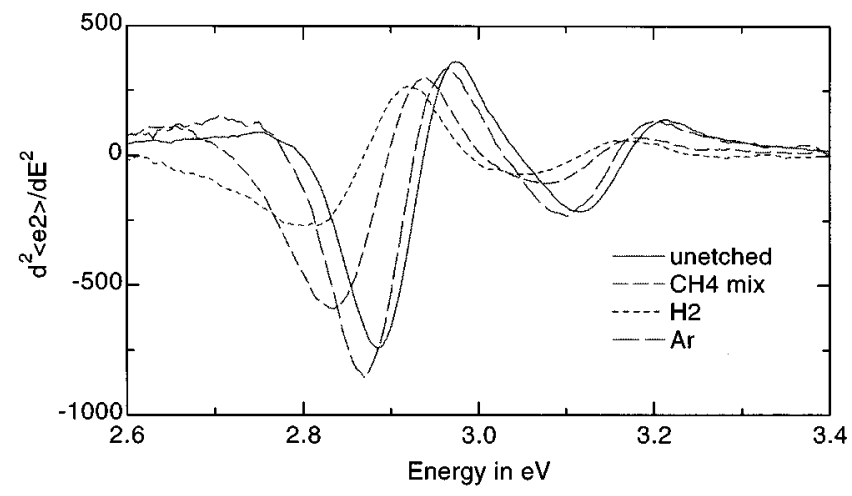

FIG. 2. Second derivatives of ex situ $\left\langle\epsilon_{2}\right\rangle$ measured for unetched sample and samples etched as described in text.

broadening than the methane mixture. Argon etching causes very little redshift.

To determine bulk etch rates, a small surface region was covered by silver paint during the etch, then the paint was removed, and the step height measured by profilometer. Etch rates were about $26 \mathrm{~nm} / \mathrm{min}$ for the methane $\mathrm{mix}, 37 \mathrm{~nm} / \mathrm{min}$ for pure hydrogen, and $33 \mathrm{~nm} / \mathrm{min}$ for the argon. These results are consistent with previously reported etch rates under similar conditions. ${ }^{1}$

To determine the approximate thickness of the redshifted GaAs layer, a sample was etched first with the methane mix for several minutes (as in Fig. 1), then with argon. Figure 3 shows a sequence during argon etching. As the argon etch removes the redshifted layer, $E_{1}$ gradually blueshifts back towards its original value (the reverse of Fig. 1). Most of the redshifted layer is gone within 1 min implying that the redshifted layer due to methane etching is no more than about $30 \mathrm{~nm}$ thick. Similar runs were made starting with a hydrogen etch instead of the methane mix. These redshifted layers required several times as long to etch away.

In order to model the real time SE data (Fig. 1) for thicknesses, the optical constants of the redshifted layer were needed. These were obtained from the in situ data at a fixed point in time, after $1 \mathrm{~min}$ of etching with the methane mix (similar to the $48 \mathrm{~s}$ spectrum of Fig. 1). It was assumed that the surface region then consisted of a single layer of red-

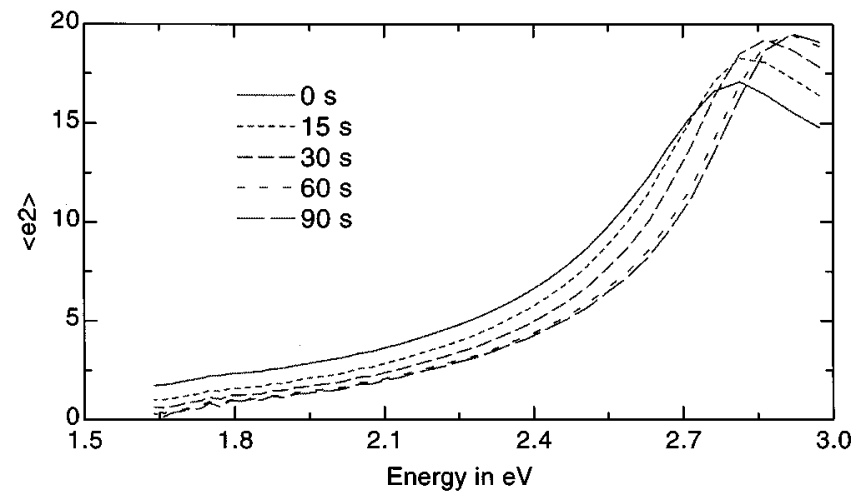

FIG. 3. In situ $\left\langle\epsilon_{2}\right\rangle$ measured during Ar etching of GaAs that was previously etched with the methane mixture. 
shifted material on GaAs bulk material. A simple empirical model, the harmonic oscillator (HO), was used for the redshifted optical constants. The HO model has been used previously to model the optical constants of crystalline GaAs (Ref. 5) and AlGaAs. ${ }^{8,9}$ Using a seven oscillator model for crystalline GaAs as a starting point, the amplitude, broadening, and energy of the $E_{1}$ oscillator were allowed to vary, along with the amplitude of a higher lying oscillator. The thickness of the redshifted layer was also allowed to vary. As expected, the resulting dielectric function displayed a redshifted and broadened $E_{1}$ feature. It was possible to obtain a good fit by varying just four of the total 21 oscillator parameters because the in situ spectral range included only the $E_{1}$ feature. The layer thickness best fit value was about $15 \mathrm{~nm}$, of the same magnitude as the argon etching result from Fig. 3 , but a factor of 2 lower. This difference may be due in part to the simplifying assumptions used in the modeling result, particularly that the redshifted layer was uniform rather than graded.

Discussion: The above described measurements of etched bulk GaAs indicate a redshifting of the $E_{1}, E_{1}+\Delta_{1}$ critical points in the top few tens of $\mathrm{nm}$, associated with the presence of hydrogen in the plasma. We now consider the possible causes of the redshift. Ion implantation has been shown to convert the crystal near the surface into partly amorphous material. ${ }^{5}$ This causes a broadening of the $E_{1}, E_{1}+\Delta_{1}$ critical point structure (in fully amorphous material the critical point structure is not resolved), but no shifting. Therefore simple amorphous damage, although likely present to some degree, is not the cause of the redshifting.

Effects that are known to cause critical point energy shifts include temperature, alloying, and strain. The temperature dependence of GaAs optical constants is known; ${ }^{10,11}$ in fact, SE can serve as a reasonably accurate thermometer of surface temperature. ${ }^{11}$ Increasing temperature broadens and redshifts the critical points, as in Fig. 1. However, the redshift here is irreversible, as shown by the ex situ data in Fig. 2, so it cannot be a temperature effect. Similarly, alloying with indium or antimony would cause redshifting and some broadening. There is no known source of these elements in the plasma, however, and Auger electron spectroscopy (AES) measurements did not show the presence of any new elements after etching.

The relation between strain and critical point shift has been calculated in a perturbation approximation. ${ }^{12}$ Hydrostatic strain (isotropic change in lattice constant) causes an equal shift of $E_{1}$ and $E_{1}+\Delta_{1}$ in the same direction. The shift observed here, $\sim 50 \mathrm{meV}$ for the methane mixture etch, is consistent with hydrostatic strain corresponding to an $\sim 1 \%$ increase in lattice constant. Independent experimental verification that the lattice constant increased in the redshifted layer was not obtained. However, of the effects listed above this seems to be the only viable one for explaining the redshift.

Others have also reported damage due to ECR plasma etching at room temperature. Constantine et al. observed changes in photoluminescence intensity and $I-V$ characteristics when using a methane mixture with $\mathrm{rf}$ bias. ${ }^{1}$ Weegels et al. observed large changes in the in situ reflectivity spec-

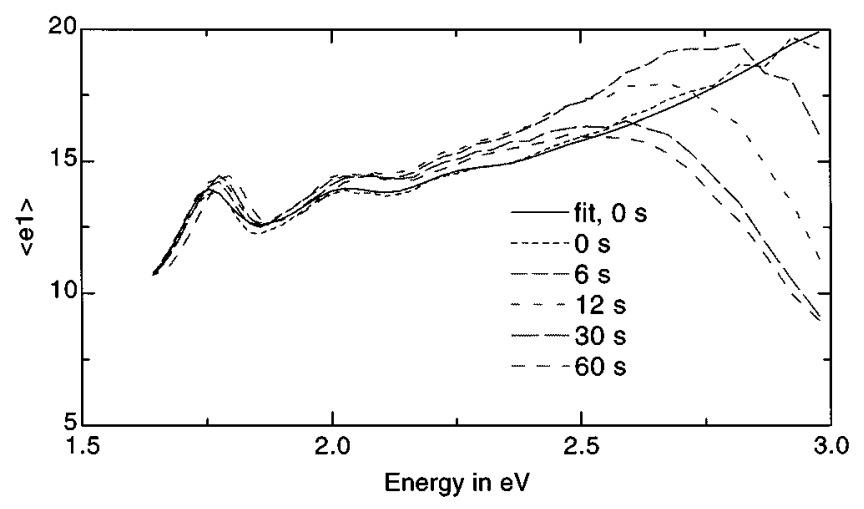

FIG. 4. Real part of pseudodielectric function measured during initial stages of $\mathrm{AlGaAs} / \mathrm{GaAs}$ heterostructure etching with the methane mixture.

trum during room temperature hydrogen ECR etching with bias, ${ }^{13,14}$ which they interpreted with a model that had a damage layer containing amorphous and crystalline GaAs. Their results for Ar etching, like ours, showed much less change in critical point structure than the room temperature hydrogen etching. In earlier work we described ECR etching of GaAs with a $\mathrm{CCl}_{2} \mathrm{~F}_{2} / \mathrm{O}_{2}$ gas mixture ${ }^{15,16}$ at much lower power and consequently a very low etch rate. There was no redshift at all in that case, only a thin damage layer a few nm thick that could be modeled as partly amorphous.

The mechanism by which hydrogen causes the redshift is presently unknown. AES measurements showed a Ga rich surface for the hydrogen etch. This result implies a possible connection between stoichiometry and redshifting. We hypothesize that hydrogen reacts preferentially with arsenic within the lattice and that, as the product (reported as $\operatorname{arsine}^{17}$ ) volatizes, it leaves the near surface region nonstoichiometric and less dense than before, allowing the remaining material to expand slightly. The ready penetration of GaAs by hydrogen can explain the relatively large thickness of the redshifted layer. Some crystal damage must accompany the arsenic removal, thus accounting for the broadening observed. Note that even pure argon etching caused a small but measurable redshift, implying a small degree of straininducing damage for this case as well. However, most of the damage was amorphous. This material could be modeled reasonably well (but without reproducing the small redshift) with a damage layer about $5 \mathrm{~nm}$ thick modeled as an EMA mixture of amorphous GaAs (Ref. 18) and voids.

\section{AIGaAs HETEROSTRUCTURE ETCHING}

Figure 4 shows in situ spectra measured during the first minute of etching by a $\mathrm{CH}_{4} / \mathrm{H}_{2} / \mathrm{Ar}$ mixture with flow rate ratios of 5/15/7, total pressure of $1 \mathrm{mTorr}$, microwave power of $300 \mathrm{~W}$, and $-200 \mathrm{~V} \mathrm{dc}$ bias. Before etching began, the data could be fit (solid line) with $1.6 \mathrm{~nm} \mathrm{GaAs}$ oxide $^{19}$ on $507 \mathrm{~nm} \mathrm{Al} \mathrm{Ga}_{1-x} \mathrm{As}, x=0.28$, on a GaAs substrate. The starting $\mathrm{AlGaAs}$ layer thickness is greater than the light penetration depth in the range $2.5-3 \mathrm{eV}$, so the underlying $\mathrm{GaAs}$ is not probed in this range initially. The $\mathrm{AlGaAs} E_{1}$ feature is higher in energy than the GaAs $E_{1}$, and initially lies outside 


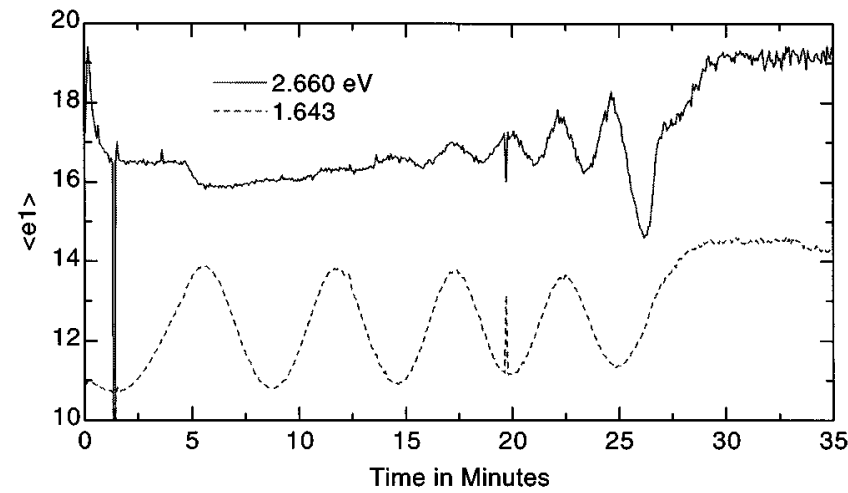

FIG. 5. Real time $\left\langle\epsilon_{1}\right\rangle$ data at above and below gap photon energies during AlGaAs etching.

the in situ spectral range. Interference oscillations due to the AlGaAs layer are seen in the transparent below gap region, becoming damped above the band gap $(\sim 1.85 \mathrm{eV})$.

During the first minute of etching, the main effect is the redshifting of the AlGaAs $E_{1}$ feature into the observed spectral range. In $\left\langle\epsilon_{1}\right\rangle$ this appears as an anomalous dispersion region rather than a peak as in $\left\langle\epsilon_{2}\right\rangle$. It broadens as it redshifts, and the amplitude of the feature decreases. The redshifting begins immediately, and has stabilized within $1 \mathrm{~min}$. In these respects the effect of etching on AlGaAs is very similar to that on GaAs.

Etching also continuously reduces the AlGaAs layer thickness. Figure 5 shows real time data at above and below gap photon energies. The above gap photon energy has a short penetration depth, less than $100 \mathrm{~nm}$; consequently it is sensitive only to the near surface region. The large change in the first minute is due to $E_{1}$ redshifting. (The spikes at 1.4 and $19.7 \mathrm{~min}$ are due to noise.) At $4.6 \mathrm{~min}$ the microwave power is increased, resulting in a change in the surface condition that this photon energy is sensitive to. As the AlGaAs layer thins further, interference oscillations begin and grow in amplitude. The abrupt end of the oscillations at $26.8 \mathrm{~min}$ signals that the undamaged AlGaAs is gone. During the next 2 min, the remaining redshifted AlGaAs is removed, and the redshifted GaAs layer develops. The below gap photon energy measurement is less sensitive to the redshifted surface region and more sensitive to the overall thickness of the AlGaAs layer due to its transparency at this energy.

Quantitative modeling of the data requires optical constants of the redshifted AlGaAs layer. These were approximated with the $\mathrm{HO}$ model, as for GaAs, fitting to the data at $1 \mathrm{~min}$. The results were similar: a redshifted and broadened $E_{1}$ peak (compared to crystalline AlGaAs, $x=0.28$ ) and a thickness of about $12 \mathrm{~nm}$. These optical constants were used in the following model to obtain layer thicknesses: GaAs substrate, AlGaAs layer ( $x$ fixed to 0.28 ), and redshifted AlGaAs layer on top. Both layer thicknesses were allowed to vary, as the measured spectra from each point in time were fit sequentially. The thickness of the AlGaAs layer determined in this way is shown in Fig. 6. The power increase at 4.6 min resulted in a noticable increase in etch rate. At the same time, the redshifted layer thickness (not shown) increased about 1

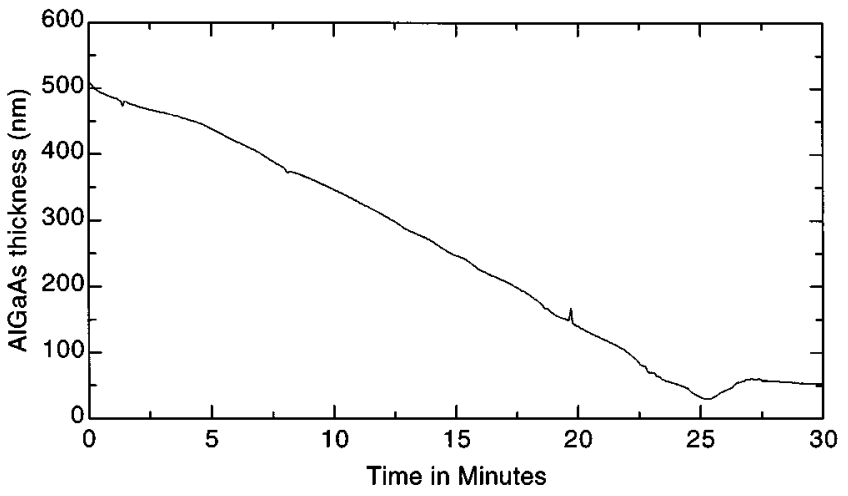

FIG. 6. AlGaAs thickness solutions from real time data. The $90 \%$ confidence limit averages $2 \mathrm{~nm}$ from 0 to $20 \mathrm{~min}$, then decreases gradually before rising again after $25 \mathrm{~min}$.

$\mathrm{nm}$, indicating a slightly thicker damage layer. This model worked well until the AlGaAs layer was nearly gone. After $25 \mathrm{~min}$ the solutions for thickness became unreliable. A straight line fit to the thickness between 5 and 20 min gives an etch rate of about $20 \mathrm{~nm} / \mathrm{min}$. The above analysis was performed after the fact on stored data rather than in real time. However, once the redshifted layer optical constants are determined, all layer thickness fits can be performed in real time during the etch.

These results show that real time spectroscopic ellipsometry can track the thickness of the AlGaAs layer (and thereby the etch rate), as well as the damage to the surface region. This information could be used to stop the etch at any desired thickness of the AlGaAs. To improve accuracy the endpoint could be predicted in advance, using real time thickness fits to determine the etch rate and predict the time at which the desired thickness will be reached.

\section{CONCLUSION}

Spectroscopic ellipsometry was used to investigate damage caused by electron cyclotron resonance plasma etching. A damage layer as much as several tens of nm thick was produced by $\mathrm{CH}_{4} / \mathrm{H}_{2} / \mathrm{Ar}$ or pure hydrogen etching with rf bias on the sample. The effect on the optical constants was to redshift and broaden the critical point structure of the GaAs and AlGaAs. We hypothesize that the redshifting is due to crystal lattice expansion, while broadening is due to amorphous damage. Ar etching caused relatively little damage. Real time ellipsometry data were also used to determine AlGaAs layer thickness, from which the etch rate was determined. Ellipsometry is very sensitive to both the surface region damage and the overall thickness of the epitaxial layer.

\section{ACKNOWLEDGMENT}

The research was supported by U. S. Air Force Contract No. F33615-93-C-1297.

${ }^{1}$ C. Constantine, D. Johnson, S. J. Pearton, U. K. Chakrabarti, A. B. Emerson, W. S. Hobson, and A. P. Kinsella, J. Vac. Sci. Technol. B 8, 596 (1990). 
${ }^{2}$ R. M. A. Azzam and N. M. Bashara, Ellipsometry and Polarized Light (North-Holland, Amsterdam, 1977).

${ }^{3}$ G. E. Jellison, Jr., Appl. Opt. 30, 3354 (1991).

${ }^{4}$ D. E. Aspnes, J. B. Theeten, and F. Hottier, Phys. Rev. B 20, 3292 (1979).

${ }^{5}$ M. Erman, J. B. Theeten, P. Chambon, S. M. Kelso, and D. E. Aspnes, J. Appl. Phys. 56, 2664 (1984).

${ }^{6}$ P. G. Snyder, J. A. Woollam, S. A. Alterovitz, and B. Johs, J. Appl. Phys. 68, 5925 (1990).

${ }^{7}$ C. M. Herzinger, H. Yao, P. G. Snyder, F. G. Celii, Y.-C. Kao, B. Johs, and J. A. Woollam, J. Appl. Phys. 77, 4677 (1995).

${ }^{8}$ F. Terry, Jr., J. Appl. Phys. 70, 409 (1991).

${ }^{9}$ M. Erman, J. B. Theeten, N. Vodjdani, and Y. Demay, J. Vac. Sci. Technol. B 1, 328 (1983).

${ }^{10} \mathrm{P}$. Lautenschlager, M. Garriga, S. Logothetidis, and M. Cardona, Phys. Rev. B 35, 9174 (1987).
${ }^{11}$ H. Yao, P. G. Snyder, and J. A. Woollam, J. Appl. Phys. 70, 3261 (1991).

${ }^{12}$ F. H. Pollak, Semiconductors and Semimetals, edited by T. P. Pearsall (Academic, Boston, 1990), Vol. 32, p. 40.

${ }^{13}$ L. M. Weegels, T. Saitoh, H. Oohashi, and H. Kanbe, Appl. Phys. Lett. 64, 2661 (1994).

${ }^{14}$ L. M. Weegels, T. Saitoh, and H. Kanbe, Appl. Phys. Lett. 65, 3117 (1994).

${ }^{15}$ N. J. Ianno, S. Nafis, P. G. Snyder, B. Johs, and J. A. Woollam, Appl. Surf. Sci. 63, 17 (1993).

${ }^{16}$ S. Nafis, N. J. Ianno, P. G. Snyder, W. A. McGahan, B. Johs, and J. A. Woollam, Thin Solid Films 233, 253 (1993).

${ }^{17}$ T. R. Hayes, M. A. Dreisbach, P. M. Thomas, W. C. Dautremont-Smith, and L. A. Heimbrook, J. Vac. Sci. Technol. B 7, 1130 (1989).

${ }^{18}$ A. Gheorghiu and M.-L. Theye, Philos. Mag. B 44, 285 (1981).

${ }^{19}$ S. Zollner, Appl. Phys. Lett. 63, 2523 (1993). 